NBER WORKING PAPER SERIES

\title{
RECENT FLATTENING IN THE HIGHER EDUCATION WAGE PREMIUM: POLARIZATION, SKILL DOWNGRADING, OR BOTH?
}

\author{
Robert G. Valletta \\ Working Paper 22935 \\ http://www.nber.org/papers/w22935 \\ NATIONAL BUREAU OF ECONOMIC RESEARCH \\ 1050 Massachusetts Avenue \\ Cambridge, MA 02138 \\ December 2016
}

Prepared for presentation at the NBER Conference on Research in Income and Wealth, "Education, Skills, and Technical Change: Implications for Future U.S. GDP Growth," Bethesda, Maryland, October 16-17, 2015. The author thanks David Autor for his highly constructive and detailed discussant comments, the editors of this volume (Chuck Hulten and Valerie Ramey) for their guidance with revisions, and participants in this conference and also the May 2016 Society of Labor Economists annual meetings for additional helpful comments. He also thanks Catherine van der List for outstanding research assistance. The views expressed herein are those of the author and do not necessarily reflect the views of the Federal Reserve Bank of San Francisco, the Federal Reserve System, or the National Bureau of Economic Research.

NBER working papers are circulated for discussion and comment purposes. They have not been peer-reviewed or been subject to the review by the NBER Board of Directors that accompanies official NBER publications.

(C) 2016 by Robert G. Valletta. All rights reserved. Short sections of text, not to exceed two paragraphs, may be quoted without explicit permission provided that full credit, including (C) notice, is given to the source. 
Recent Flattening in the Higher Education Wage Premium: Polarization, Skill Downgrading, or Both?

Robert G. Valletta

NBER Working Paper No. 22935

December 2016

JEL No. I23,J24,J31

\section{ABSTRACT}

Wage gaps between workers with a college or graduate degree and those with only a high school degree rose rapidly in the United States during the 1980s. Since then, the rate of growth in these wage gaps has progressively slowed, and though the gaps remain large, they were essentially unchanged between 2010 and 2015. I assess this flattening over time in higher education wage premiums with reference to two related explanations for changing U.S. employment patterns: (i) a shift away from middle-skilled occupations driven largely by technological change ("polarization"); and (ii) a general weakening in the demand for advanced cognitive skills ("skill downgrading"). Analyses of wage and employment data from the U.S. Current Population Survey suggest that both factors have contributed to the flattening of higher education wage premiums.

Robert G. Valletta

Federal Reserve Bank of San Francisco

101 Market St.

San Francisco, CA 94105

rob.valletta@sf.frb.org 


\section{Recent Flattening in the Higher Education Wage Premium: Polarization, Skill Downgrading, or Both?}

\section{Introduction}

Holding a four-year college degree confers a distinct advantage to workers in the U.S. labor market. The wage gaps between college-educated working adults and those with a high school degree — higher education wage premiums — are large and have grown substantially over the past 35 years. This gap may have been bolstered by technological advances in the workplace, notably the growing reliance on computers and related technologies, because the skills that are needed to master and apply these technologies are often acquired through or associated with higher education (Krueger 1993; Autor, Katz, and Krueger 1998; Autor, Levy, and Murnane 2003; Acemoglu and Autor 2011).

The expansion of the higher education wage premium has not been completely uniform over time, however, with rapid growth in the 1980s followed by progressively slower growth ("flattening"). During the years 2000 through 2010, the wage premium for college-educated workers rose by only a small amount. Most recently, from 2010 to 2015, the wage premium for those with college and graduate degrees was largely unchanged, suggesting that the factors propelling its earlier rise have disappeared.

While the wage advantage associated with higher education remains large, the lack of growth in recent years represents a departure from the earlier pattern. This change may have important implications for the value of higher education as an individual and social investment and consequences for economic growth as well. Despite the voluminous literature on returns to education, little attention has been paid to slower growth in the college wage premium and differences between these higher education groups (Lindley and Machin 2014 is an exception). 
In this paper, I assess and attempt to explain the stalling of the higher education wage premium and its variation across the college-only and graduate degree groups. I focus on two primary, related explanations for changing returns to higher education.

The first potential explanation is labor market "polarization" (Acemoglu and Autor 2011). This theory emphasizes a shift away from middle-skilled occupations driven largely by technological change. It provides a broad, cohesive explanation for changes in employment patterns in the United States and other advanced economies in recent decades. Polarization may account for the slowdown in the college wage premium through a shift in the occupational distribution of college graduates towards jobs that are being displaced by automation technologies and related factors (such as outsourcing and rising trade). At the same time, rising demand for the cognitive skills possessed by graduate degree holders may help maintain and expand their wage advantage relative to those holding a four-year college degree only (Lindley and Machin 2014)

I will refer to the second broad potential explanation for the flattening of higher education wage premiums as "skill downgrading," based on the recent work of Beaudry, Green, and Sand (BGS 2016). They emphasize a general weakening since the year 2000 in the demand for cognitive tasks in the workplace, reflecting a maturation in the information technology (IT) revolution and consequent slowdown in workplace IT investments. Skill downgrading in their framework refers to the process by which weaker demand for advanced cognitive skills cascades down the skill distribution as highly skilled workers, such as those possessing advanced degrees, increasingly compete with and replace lower-skilled workers in occupations that rely less heavily on advanced cognitive skills. 
I begin my empirical assessment in the next section by establishing the basic facts regarding changes in educational attainment and the higher education wage premiums, distinguishing between individuals with a four-year college degree and those with graduate degrees. The analyses throughout are based primarily on data from the Current Population Survey (CPS) monthly earnings files (monthly outgoing rotation groups, or MORG), which cover the period 1979-2015. I also conduct selected parallel analyses using the CPS Annual Social and Economic Supplement files (March CPS ASEC), which at the time of this writing provide earnings data through 2014. Standard wage regressions that adjust for changing workforce composition pin down the flattening of the higher education wage premiums noted above.

To help interpret these empirical findings, I then discuss the polarization and skill downgrading arguments in more detail. Observed occupational employment shifts indicate the potential importance of polarization for the flattening of the college wage premium. The BGS skill downgrading narrative takes polarization as its starting point but emphasizes different dynamics over time, with weaker demand for cognitive skills arising as a consequence of a slowdown in technology investment.

To assess the effects of polarization and skill downgrading on higher education wage premiums, I examine changing premiums within and between the broad occupation categories that are used to identify the extent of polarization. The results of these analyses suggest that polarization and skill downgrading have both contributed to the flattening of the wage premium for individuals with a four-year college degree or post-graduate degree. Consistent with the polarization story, the flattening in the wage premium is partly explained by shifting employment and relative wages across broad occupational groups, mainly for those with a college degree but 
no graduate degree. However, a substantial contribution also comes from the slowdown in the wage premium within broad occupation categories, consistent with skill downgrading and heightened competition between educational groups for similar jobs. In the Conclusion, I discuss the implications of these findings for future research on the returns to higher education and its role in economic growth.

\section{Changes in the higher education wage premium}

The wage premium earned by individuals with higher educational attainment is commonly attributed to the more extensive skills that they possess (Card 1999, Goldin and Katz 2008). To save space, I will not review the voluminous and well-known literature on estimating and interpreting the returns to education but will instead turn directly to updated estimates of the returns to higher educational attainment (college degrees and above).

\subsection{Data and descriptive statistics}

Because the data and processing procedures I use are well-known, I describe them only briefly here, with additional details relegated to Appendix A. The primary data used are from the CPS MORG files, compiled by the National Bureau of Economic Research (NBER) and currently covering the years 1979-2015. These files contain data for the quarter sample of the monthly CPS that receives survey questions regarding earnings and related variables in currently held jobs. I also use the complete monthly CPS files for selected tabulations that do not involve wages.

The data handling and processing procedures largely follow those detailed in Lemieux (2006b, 2010). These include elimination of observations with imputed values of earnings or hours and adjustments for changing top-codes. I use hourly wages as my earnings measure, either reported directly by hourly workers or formed as usual weekly earnings divided by usual 
weekly hours worked for salaried workers. All wage and earnings variables are deflated by the annual average value of the GDP deflator for personal consumption expenditures (and expressed in 2015 terms for ease of interpretation). For all of the analyses in this paper, the samples are restricted to wage and salary workers age 25-64 (with farming and resource occupations excluded).

The basis for the measurement of educational attainment in the CPS switched in 1992 from the highest grade attained and completed to the highest degree received. I formed educational categories that are largely consistent over time following the guidance of Jaeger (1997). ${ }^{1}$ Individuals with a graduate degree, along with information about the type of degree, are directly identified beginning in 1992. Graduate degree holders prior to 1992 are identified as those reporting at least 18 years of completed education. I code individuals who report 17 years of completed schooling in the pre-1992 period as possessing a 4-year college degree but not a graduate degree. $^{2}$

For comparison purposes, I also use data from the March CPS files to estimate changes in the higher education earnings premium. Compared with the MORG data, which provides information on earnings in the current reference week, the March CPS data refer to earnings in the complete prior calendar year. Following standard practice, I restrict the March CPS sample to full-time, full-year workers and use weekly earnings (annual labor earnings divided by weeks worked) as the earnings measure, once again dropping observations with imputed earnings or

\footnotetext{
${ }^{1}$ Relative to Jaeger (1997), in the 1992-forward data I include individuals who report 12 years of schooling but no diploma in the "no degree" group rather than the "high school degree" group, to be consistent with the emphasis on degree attainment beginning in 1992.

${ }^{2}$ Lindley and Machin (2014) take a similar approach, which groups individuals who drop out of a graduate program after one year or complete a one-year Master's degree program with those who complete a four-year college degree only. This approach generates a slight discontinuity in the relative college/graduate shares in 1992, but the discontinuity is larger if instead such individuals are treated as having a graduate degree.
} 
hours and adjusting for changing top-codes (e.g., Autor, Katz, and Kearney 2008). These files are currently available through 2015 . Since the data refer to the prior calendar year, the reference period for the March data ends one year earlier than the MORG data (2014 rather than 2015).

Table 1 provides descriptive statistics for employment shares (Panel A) and average real wages (Panel B) by educational attainment, calculated using the full monthly CPS files for the employment shares and the MORG files for the wage data. These are provided for 10-year intervals that largely span the sample frame. The table also lists statistics for selected other years, including the year that the education variables changed (1992) to bridge the gap in definitions, and a listing for the final data year (2015).

Panel A of Table 1 illustrates the well-known, steady decline in the employment share of individuals whose educational attainment is a high school degree or less accompanied by a steady rise in the share of individuals possessing a four-year college degree or graduate degree. As of 2015, nearly 40 percent of employed individuals age 25-64 held a college degree, and one in seven held a graduate degree, accounting for slightly more than a third of employed college graduates. Master's degrees (which include MBAs) account for most of the level and change in the fraction holding graduate degrees, along with a large proportional increase for the small share of doctoral degrees.

Panel B of Table 1 illustrates the large wage gaps between the educational attainment groups, with the spread in real wages between the graduate degree group and those with less than a high school degree widening approximately from a factor of two to a factor of three over the sample frame. Average real wages changed little over the sample frame for those with a high school degree or less. For those with at least some college education, average real wages rose somewhat between 1980 and 2000, with larger increases evident for those with higher 
educational attainment. Between 2000 and 2010, only holders of graduate degrees saw any meaningful increase in real wages. Between 2010 and 2015, real wages were flat to down slightly for all groups. The gap in average real wages between individuals with a four-year college degree or graduate degree and high school graduates rose from 40-67 percent in 1980 to 72-120 percent as of 2015 .

\subsection{Composition-adjusted estimates of wage gaps}

To assess the changing wage premium associated with higher educational attainment, I estimate standard log wage equations of the following form (where $i$ indexes individuals):

$$
\ln W_{i}=X_{i} \beta+S_{i} \Gamma+\varepsilon_{i}
$$

$X_{i}$ represents a set of demographic controls and $S_{i}$ represents educational attainment. This equation is estimated separately for each year using the MORG and March CPS data as described above. The control variables in the vector $X$ include dummy variables for seven age groups (e.g., 30-34, etc., with 25-29 omitted), three racial/ethnic groups, gender, marital status, gender*marital status, and geographic location (nine Census divisions). These controls adjust for the changing composition of the estimation sample, so that the results for the education categories reflect the average wage premium associated with educational attainment for an individual with a fixed set of other demographic characteristics. ${ }^{3}$

Our interest centers on the estimated vector of coefficients $(\Gamma)$ on a set of dummy variables representing discrete categories of educational attainment $(S)$. Table 2 lists the numerical results for selected years, while Figure 1 displays the results for the complete sample

\footnotetext{
${ }^{3}$ The results reported below are very similar when this set of control variables is replaced by complete interactions between four decadal age categories, four race/ethnic categories, the two genders, and marital status (married spouse present or not), for a total of 64 demographic cells.
} 
period of 1979 through 2015. For both displays, Panel A lists the results for the MORG data, while Panel B lists the results for the March CPS. The results are expressed in natural log terms. These conditional wage gaps are displayed for three educational groupings: the broad group of all workers with at least a four-year college degree, and the two sub-groups consisting of those with a four-year degree only (“college only") and those who hold a post-graduate degree as well. The results for the "college degree or higher" group are based on regressions that are estimated separately from the one used to estimate the returns for the two sub-groups (as indicated by the horizontal line breaks in the table). The higher education wage premiums are first expressed relative to the wages of high school graduates. In addition, separate estimates are provided for those holding a graduate degree. These are based on the restricted sample of individuals who have at least a college degree, hence they represent the graduate wage premium relative to the wages of the college only group (displayed separately in Figure 2).

The estimates in Table 2 and Figure 1 show that the wage premiums for higher education generally have been rising over time. However, both data sets shows that the growth has slowed in recent decades, with the slowdown for the graduate group lagging behind that for the collegeonly group. The rate of growth in the college-only wage premium was cut approximately in half between the 1980s and 1990s and then slowed virtually to a standstill after 2000. It rose about 2$2.5 \log$ points through 2010 and then was unchanged between 2010 and 2015.

For the graduate degree group, the slowdown over time is most evident based on the results for the college or higher sample. These are displayed at the bottom of both panels in Table 2 and also in Figure 2, where the results for the MORG and March data sets are directly compared. The estimated wage premiums are very similar in the two data sources, with somewhat greater annual volatility evident in the March data for the college-only sample in 
Figure 2 due to its smaller sample. Relative to the college-only group, individuals with a graduate degree saw consistent wage premium gains of about 4-5 log points in each of the decades from the 1980s, 1990s, and 2000s. During this timeframe, their wage advantage over college-only workers grew steadily, reaching nearly $25 \log$ points by 2010. However, since 2010, the graduate degree premium is down slightly in both data sources (through 2015 in the MORG data and 2014 in the March data).

\subsection{Robustness checks and disaggregation by age and gender}

One potential concern with respect to these results is the possibility that they reflect underlying changes in employment conditions among narrow worker groups or industries. Such narrow changes may be independent of the broad occupational changes and shifting labor market competition related to polarization and skill downgrading (which are analyzed and discussed below, in Section 4). One such narrow group is teachers, who constitute a substantial but declining share of employed college graduates. ${ }^{4}$ Excluding educator and librarian occupations from the regressions raises the estimated higher education wage premiums by 2-4 log points in general. However, the pattern over time is unchanged relative to the full sample results, with progressive flattening in the wage premiums and no change from 2010 forward.

It is also important to consider the potential influence of changing conditions in key industries that employ large numbers of college graduates. One such industry is the financial sector, for which the housing bust and financial crisis tied to the Great Recession of 2007-09 destroyed a disproportionate number of jobs. Many finance sector jobs are highly paid, and their disappearance may have affected the higher education wage premium. However, exclusion of workers employed in the financial, insurance, and real estate sectors from the regression analysis

\footnotetext{
${ }^{4}$ Among workers with at least a four-year college degree in the MORG data, the fraction of educators and librarians declined by a third over my sample frame, from 24 percent in 1979 to about 16 percent in 2015.
} 
has virtually no impact on the estimate wage premiums and their pattern over time. ${ }^{5}$ Similarly, BGS (2016) highlight the role of the business and management services industries for their findings, emphasizing substantial employment changes for young college graduates in this sector. Exclusion of individuals employed in these industries does not affect the estimated college-only wage premium. It does raise the level of the graduate school wage premium, suggesting a relatively low value for graduate degrees in this industry. Nonetheless, the pattern of the higher education wage premiums over time, as reflected in the results from Table 2 and Figure 1, is unaffected.

It is also instructive to examine the higher education wage premium decomposed by age group and gender. Analyses of employment and wage patterns for the college educated often highlight younger workers, who are likely to experience the most immediate effects of changing employment conditions across educational attainment groups (e.g., BGS 2014). Figure 3 parallels Figure 1 (Panel A, MORG) but displays wage premiums for the youngest decadal age group in my sample (age 25-34) in Panel A and an older group (age 45-54) in Panel B. ${ }^{6}$ For younger workers, movements in the wage premiums over time largely parallel those for the complete sample in Figure 1, with large gains in the 1980s followed by slower gains in the 1990s and 2000s and no change since 2010. By contrast, for older workers the college-only premium was largely flat in the 1990s, perhaps because this group did not readily adapt to the new information technologies introduced during that decade. The college-only premium for older workers picked up in the 2000s, although like the graduate degree premium it has been flat since

\footnotetext{
${ }^{5}$ Separate analyses by broad industry, also noted in Section 4, show that the higher education wage premiums within the finance sector broadly track the patterns evident for the overall economy.

${ }^{6}$ The underlying regressions used to produce the results in Figure 3 are identical to those used for Table 1 and Figure 1, except the samples are restricted to the indicated age groups and the age category controls are adjusted accordingly. I use age 45-54 rather than the oldest group in my sample, age 55-64, to minimize the influence of partial retirement decisions on relative earnings over time.
} 
2010. Comparison across the two panels in Figure 3 also indicates that the higher education wage premiums are larger for older than for younger workers, by about 5-10 log points on average. This likely arises due to important interaction or reinforcing effects between higher education and the subsequent acquisition of on-the-job skills that raise wages as workers age.

Given the well-known increase in the attainment of higher education for women relative to men, it is also informative to examine the wage premiums by gender. These are displayed in Figure 4 (Panel A for men, Panel B for women). The series represent the composition-adjusted higher education wage premiums by gender; as such, they reflect relative wages within gender group and hence should not be interpreted as capturing wage differences between men and women. The higher education wage premiums are larger for women than for men, although the gap has closed over time, especially for graduate degrees. The pattern over time for both genders is similar to that for the overall sample in Figure 1 (Panel A), with a flattening of the wage premiums over time and essentially no change since 2010.

\subsection{Summing up: higher education wage premiums over time}

The results presented in this section indicate general flattening in the wage premiums associated with four-year college and graduate degrees. The sharp increases observed in the 1980s have been followed by much slower gains. Since the year 2000, the wage premium associated with a four-year college degree has changed little. By contrast, from 2000-2010, the wage premium for holders of graduate degrees relative to those with four-year college degrees continued to grow at its previous pace, contributing to increasing "convexification" in the returns to higher education (Lemieux 2006a, Lindley and Machin 2014). Since 2010, however, wage premiums for both groups have sputtered. They remain large but were essentially unchanged for 
the college-only group and down slightly for holders of graduate degrees. These patterns indicate that the factors propelling earlier increases in the returns to higher education have dissipated.

Because of the significant time required for individual investments in higher educationfour years or more - the flatter wage premiums may reflect a delayed response of the supply of college-educated individuals to earlier increases in demand (Acemoglu and Autor 2011, Autor 2014). However, given the relatively consistent increase over time in the college-educated employment share listed in Table 1 (Panel A), factors on the demand side that affect relative productivity and employers' preference for workers with higher education merit further consideration.

\section{Potential explanations: polarization and skill downgrading}

The slower growth and eventual flattening in the wage premium for higher education documented in the preceding section raises the possibility that the factors propelling rising wage premiums for highly skilled workers have dissipated. Past accounts of rising wage premiums for skilled workers generally revolved around the skill-biased technological change (SBTC) explanation of labor market developments. Under SBTC, rising reliance on sophisticated workplace technologies boosts the employment and wages of workers, mainly the highly educated, whose skills enable them to apply those technologies (e.g., Bound and Johnson 1992, Autor, Katz, and Krueger 1999). Recent research has pointed to factors that may alter or offset this process. I focus on two broad explanations: labor market polarization and skill downgrading.

\subsection{Polarization and skill downgrading: the basics}

The "polarization" hypothesis is a leading explanation for recent employment developments in the United States and other advanced countries (Goos and Manning 2007, Acemoglu and Autor 2011, Autor 2015, Goos, Manning, and Salomons 2014). This is a 
refinement of the SBTC story that accounts for excess employment growth in the top and bottom portions of the wage distribution, with erosion in the middle.

In the polarization framework, evolving workplace technologies undermine demand for "routine" jobs, in which workers are readily substituted by computer-intensive capital equipment and processes. They include white-collar office jobs (e.g., bookkeeping and clerical work), termed "routine cognitive" jobs, and blue-collar occupations that involve repetitive production or monitoring activities, termed "routine manual" jobs. These routine jobs are concentrated toward the middle of the wage and skill distribution. By contrast, workers in high-wage "nonroutine cognitive" (or "abstract") jobs tend to be complements with computer-based technologies, while low-wage service workers in "nonroutine manual" jobs are neither substitutes nor complements with computer-based technologies. Polarization arising from changes in domestic production technologies may be reinforced by related changes in overseas technologies, through the impact of offshoring and import competition (see e.g. Autor, Dorn, and Hanson 2013).

Beaudry et al. (BGS 2016) provide a related but alternative framework for understanding changing occupation employment patterns over the past few decades. They rely on a basic variant of the polarization hypothesis as their starting point, but they emphasize a slowdown in IT investments that has undermined the demand for cognitive skills since the year 2000. In their narrative, weaker demand for cognitive skills and the consequent impact on highly skilled workers has cascaded down the skill distribution, undermining the demand for lesser skilled workers as well. They refer to this process as "skill downgrading," which contrasts with the opposite pattern of "skill upgrading" that occurs during the initial period of accelerating IT investments. 
The similarities and contrasts between the polarization and BGS skill downgrading scenarios can be readily summarized with reference to the production functions and associated objective functions that underlie the two models. In a basic model of polarization, firms rely on cognitive and routine task inputs supplied by workers for production, combined with inputs of computer capital (see for example Autor et al. 2003). ${ }^{7}$ The firm aims to maximize profits $\pi$ by choosing appropriate input combinations given its production function $F$ :

$$
\max _{\Omega, L_{c}, L_{r}} \pi=\mathrm{p} * F\left(\Omega, L_{c}, L_{r}, \theta\right)-r \Omega-w_{c} L_{c}-w_{r} L_{r}
$$

where $p$ is the price of the firm's output, $\Omega$ is a form of technological (computer) capital with per-unit rental rate $r, L_{c}$ and $L_{r}$ are inputs of cognitive and routine labor with wage rates $w_{c}$ and $w_{r}$, and $\theta$ is a technology parameter that shifts the level of output for a given set of inputs (assumed constant in this basic version of the model, but allowed to change in the BGS variant below). The production function $F(\cdot)$ is assumed to reflect constant returns to scale and hence diminishing marginal productivity for individual inputs.

Production efficiency requires hiring labor inputs up to the point where each inputs' marginal product equals its market wage or rental rate. Importantly, Autor et al. (2003) assume that computer capital is perfectly substitutable with routine labor inputs, implying complementarity between computers and cognitive (nonroutine) labor in their setting. In this framework, as the price of computer capital falls, production shifts toward greater reliance on cognitive labor inputs and less on routine labor inputs, with corresponding reductions in the

\footnotetext{
${ }^{7}$ This representation is adapted from Autor et al. (2003), modified to be broadly consistent with the notation and framework in BGS (2016). Nonroutine manual jobs are largely ignored here, for simplicity and because they have limited relevance for college-educated workers.
} 
relative wage paid for routine labor inputs. Because routine tasks are common among many jobs toward the middle of the wage distribution, polarization will tend to erode or "hollow out" middle-class jobs and wages.

BGS extend the basic polarization model by incorporating the key feature that cognitive labor inputs create a stock of organizational capital for firms, which enables them to develop and utilize new technologies. This is captured in the following modification of equation 2 , which is a discrete-time version of the objective function from equation (1) in BGS (2016).

$$
\begin{gathered}
\max _{L_{c}, L_{r}} \pi=\mathrm{p} * F\left(\Omega, L_{r}, \theta\right)-w_{c} L_{c}-w_{r} L_{r} \\
\text { s.t. } \Delta \Omega=L_{c}-\delta \Omega_{-1}
\end{gathered}
$$

Relative to the production function in equation (2), $\Omega$ in equation (3) represents intangible "organizational capital" rather than tangible computer capital. In this modified framework, cognitive labor inputs do not directly affect current production but instead contribute to output through the accumulation of organizational capital (which depreciates at the rate $\delta$ ). The firstorder conditions for production efficiency are similar to the basic polarization model from equation (2).

This modified model is distinguished by its dynamic properties in response to a technological shift, or change in $\theta$. BGS assume that an increase or improvement in the technology factor $\theta$ raises the productivity of the organizational capital accumulated through the use of cognitive labor inputs but has no direct effect on the productivity of routine labor inputs. These model features generate a "boom-bust cycle" in the demand for cognitive tasks and overall labor demand in response to technological improvement. In particular, the dynamics of the 
model predict that the stock of cognitive tasks/skills grows during the boom, as the economy adjusts to the need for additional organizational capital to manage the new technology. Once the level of organizational capital becomes sufficiently large for appropriate use of the new technology, the demand for cognitive tasks declines as their use is shifted from expanding organizational capital to maintaining it by offsetting depreciation (similar to the pattern in existing models of technology diffusion and capital investment).

The BGS model can predict the strong growth in demand and wages for workers in jobs that rely heavily on cognitive tasks/skills up to the year 2000 - the boom phase — followed by a decline thereafter - the bust phase. The demand reversal during the bust phase causes highskilled workers to move down the occupational ladder and replace lower-skill workers, pushing the latter group further down the occupational ladder ("skill downgrading") and perhaps out of the labor market entirely. ${ }^{8}$

\subsection{Descriptive evidence}

Broad empirical evidence suggests that polarization and skill downgrading are both contributing to changing employment patterns and hence may be affecting higher education wage premiums.

Patterns of occupational job growth in recent decades confirm the relevance of the polarization narrative. Labor demand and job growth have been relatively rapid in the high-wage nonroutine cognitive and low-wage nonroutine manual categories, with the middle-wage routine jobs experiencing downward pressure. This pattern can be seen in Figure 5, which displays annual rates of job growth for the four broad polarization categories over four sub-periods

\footnotetext{
${ }^{8}$ As BGS note in their Introduction: "In this maturity stage, having a college degree is only partly about obtaining access to high-paying managerial and technology jobs - it is also about beating out less educated workers for barista and clerical-type jobs."
} 
(classified using the broad occupational scheme from Acemoglu and Autor 2011; see Appendix B for the correspondence). ${ }^{9}$ The figure shows substantial growth in the 1980 s followed by a slowdown in the 1990s for all groups (reflecting in part the impact of the early 1990s recession). ${ }^{10}$ Polarization is evident in the 1990 s, reflected in a sharper slowdown for the routine vs. the nonroutine categories. This process appeared to accelerate after the year 2000, with substantial gains for nonroutine jobs and substantial net losses for routine jobs, particularly during the Great Recession of 2007-09 and the subsequent recovery. ${ }^{11}$

Polarization will differentially affect highly educated and less educated groups due to their very different occupational distributions. Figure 6 shows the shares of the college-only and graduate degree groups in the nonroutine cognitive (Panel A) and routine cognitive (Panel B) categories. Workers with at least a college degree account for a large and rising share of nonroutine cognitive jobs, reaching nearly 70 percent by 2014 (Panel A). Underlying this pattern is a significant rise in the share of nonroutine cognitive jobs held by individuals possessing a graduate degree, with little change in the share from the college-only group. This pattern is consistent with rising demand for the most highly educated individuals in jobs that require extensive nonroutine cognitive skills. The college-only group share also has grown in the routine cognitive category (Panel B), commensurate with their rising share of the overall workforce.

\footnotetext{
${ }^{9}$ Autor (2015) relabeled the nonroutine categories and collapsed the two routine categories into a single one. I maintain the original four-group categorization based on the cognitive/manual and routine/nonroutine distinctions due to the preponderance of college graduates in each of the cognitive categories.

${ }^{10}$ The start year of 1983 was dictated by the availability of official BLS occupational employment data beginning in that year, and the change between 1999 and 2000 is omitted to eliminate the influence of a discontinuity in occupational category definitions.

${ }^{11}$ The differential growth rates across the broad occupational categories have generated significant changes in their employment shares over time. Nonroutine cognitive jobs are the largest category: their share rose from about 30 percent to slightly over 40 percent of all jobs during the sample frame. The share of routine jobs declined from nearly 60 percent to about 45 percent. The share of nonroutine manual jobs rose from about 12 to about 15 percent, mostly since the year 2000 .
} 
Figure 7 reverses the Figure 6 calculations by displaying the share of nonroutine cognitive jobs within the college-only and graduate degree groups. Among the college-only group, the fraction employed in nonroutine cognitive jobs declined between 2000 and 2015, from about 68 to 64 percent. By contrast, the share of graduate degree holders employed in nonroutine cognitive jobs has been largely stable at about 90 percent in recent years, while their overall workforce share has grown.

These tabulations suggest that polarization may be an important factor underlying the rising relative return to post-graduate education. As discussed by Autor (2015), the wage impacts of polarization depend not only on skill/technology complementarity, but also on: (i) the demand elasticity for products and services that rely heavily on the different skill/task groups; (ii) labor supply elasticity for the different skill/task groups. In regard to nonroutine cognitive jobs, both factors imply that workers in these jobs are likely to see their wages rise in response to rising reliance on computer and automation technologies (assuming that their skills are complementary with computers). Demand for their output is relatively elastic, and an inelastic supply response due to the time required for acquiring additional education implies that the supply of such workers does not respond quickly to rising demand. As such, ongoing polarization should put upward pressures on the relative wages of individuals employed in nonroutine cognitive jobs, most of whom have college or graduate degrees. ${ }^{12}$

As discussed above, the BGS “skill downgrading” alternative takes polarization as its starting point but emphasizes a more general decline in demand for cognitive skills, which may affect all educational attainment groups. BGS present evidence to support the claim that the

\footnotetext{
${ }^{12}$ Based on these considerations, Autor (2014) notes that while polarization is likely to lower wages of workers in routine skill/task occupations, wages for workers in nonroutine manual jobs are likely to be relatively unaffected by polarization, despite the favorable polarization effects on employment for that group.
} 
demand for cognitive and technological skills in the U.S. labor market has weakened since the year 2000. They focus on broad patterns in employment across occupational and educational attainment groups, distinguishing between jobs that are intensive in cognitive versus routine or manual skills. The patterns in employment growth that they document are consistent with a reversal in the demand for cognitive skills, notably a slowdown in the relative rate of employment growth for occupations that are toward the top end of the wage distribution. They also use a more detailed identification scheme for cognitive task intensive jobs and confirm the shift out of such jobs by college graduates implied by my Figure 7 (see their Figure 10).

One key element of the BGS framework and predictions is a pickup followed by a decline in technological advance, which generates the boom-bust cycle for cognitive employment and eventual skill downgrading in their model. This assumption is strongly supported by patterns in U.S. productivity growth in recent decades, depicted in Figure $8 .{ }^{13}$ The growth in output per worker measured by productivity gains generally reflects improvements in production technologies. Figure 8 shows a sharp productivity acceleration from 1995-2004, which corresponds roughly to the period of diffusion for new IT technologies that motivated the BGS model. ${ }^{14}$ This was followed by an even more pronounced downshift in productivity growth. Productivity gains were especially slow from 2010-forward, the period during which the wage premium for higher education was flat or down (as discussed in Section 2 earlier). This correspondence suggests that the BGS narrative of a technology slowdown is relevant for understanding the recent pattern in the higher education wage premium.

\footnotetext{
${ }^{13}$ I thank my colleague John Fernald for his advice with this display.

${ }^{14}$ BGS focus on the year 2000 as a dividing line for the slowdown in demand for cognitive skills. However, it is likely that firms' ability to utilize new organizational capital associated with the IT revolution, and hence increase measured productivity, continued for a time after investment in that capital and corresponding rapid expansion of cognitive jobs largely came to an end.
} 
BGS note that their model has limited implications for relative wages across skill groups. They also note, however, that a simple parametrization of their model generates the slowdown in wage growth across the skill spectrum observed during the "bust" phase, consistent with the observed slowdown in real wages beginning in the year 2000 (see my Table 1, Panel A). ${ }^{15}$ The skill downgrading narrative also can explain the recent elevated level of "underemployment" of young college graduates, defined as the tendency for them to work in jobs that do not strictly require a college degree (see Abel and Deitz 2016, forthcoming in this volume).

\section{Wage effects of polarization and skill downgrading}

The confluence of polarization and skill downgrading influences on the labor market in recent years has been noted by others. Autor (2015), Lindley and Machin (2014), and BGS (2016) all provide a balanced, informed discussion and interpretation of labor market developments from 2000 forward and acknowledge the possibility that polarization and skill downgrading may both be playing a role. Each may have contributed to the flattening of the higher education wage premiums documented in Section 2.

No sharp dividing lines between the two explanations are readily apparent. However, some insight can be gleaned by examining the wage premium patterns within and across the four broad occupation groups used in the polarization typology. The preceding analyses indicated complex changes in the employment and wage patterns of highly educated individuals across the broad polarization occupation grouping in recent years. A within-between analysis is a relatively straightforward means for combining these changes into a single set of summary results.

\footnotetext{
${ }^{15}$ The slowdown in real wage growth for all educational groups displayed in Table 1 is maintained when the data are adjusted for the same individual characteristics as used for the regression analyses in Tables 2 and 3 (using a re-weighting methodology).
} 
This analysis begins with the same wage regressions as reported in Section 2, but with separate regressions run for each of the four broad occupational groups from the polarization typology. Let $\gamma$ represent a higher education wage premium (college or more, college only, or graduate degree) estimated for a specific year based on equation (1) and reported in Table 2 . The overall premium estimate can be decomposed as follows:

$$
\begin{aligned}
\gamma & =(\text { within effect })+(\text { between effect }) \\
& =\sum_{j=1}^{4} w_{j} * \gamma_{j}+(\text { between effect })
\end{aligned}
$$

where $j$ subscripts the four broad occupation groups in the polarization typology, the $\gamma_{j}$ 's are occupation-specific estimates of the higher education premium, and the weights $w_{j}$ are set equal to the share of each occupation group in total employment.

The within component in equation (4) is defined as the employment-weighted sum of the estimated occupation-specific wage premiums. It represents the higher education wage premium conditional on occupational skill/task group. It can be interpreted as the competitive advantage enjoyed by individuals with higher educational attainment when competing directly with lesseducated individuals for similar jobs (within the broad polarization occupational groupings). As such, changes in the within component likely reflect a BGS skill downgrading effect, which causes enhanced competition across educational groups for similar jobs. The between component is obtained as the difference between the total estimate and the within component. ${ }^{16}$ It does not

\footnotetext{
${ }^{16}$ Note that the total effect corresponds to the full-sample estimates from Table 2. For example, the first total effect listed in column 1 of Table 3, 0.270, corresponds to the college-only estimate from column 1 of Panel A in Table 2.
} 
have a precise interpretation in the context of the polarization and skill downgrading narratives: a relative increase in the shares of college-educated workers in routine jobs could reflect ongoing polarization in the distribution of jobs or the process of skill downgrading. However, it is informative nonetheless to assess whether the changes in the wage premium are associated with shifts in the occupational distribution of employment by education group.

I conduct this analysis by first estimating higher education wage premiums within each of the four broad polarization occupation groups, which provide the inputs into equation (4) above. The regressions are otherwise identical to those reported in Table 2. Table 3 lists the regressions results, focusing on the college-only premium (measured relative to high school graduates) and the graduate degree premium (measured relative to the college-only group), with results for the same set of years as Table 2 listed. The panel immediately below the regressions lists the decomposition of the "total" effect into "within" and "between" components.

The regression results in Table 3 indicate that the higher education wage premiums are widely dispersed and their changes over time have been relatively consistent across the occupation groups. The exception is routine manual jobs, in which the higher education wage premium is relatively small for both education groups: the college-only premium is about half its size relative to the estimates for the other three groups, and the graduate premium is not statistically different from zero.

These patterns imply that increases in the total effect over time have been primarily driven by changes in the within component, with limited movement in the between component. This is confirmed by the results listed in Table 3 for selected years and displayed in Figure 9 for the complete sample frame. The within component, representing a competitive advantage to higher education within broad occupation groups, accounts for virtually all of the increase in the 
higher education wage premiums over time. However, the between component contributed to a slight increase in the wage premiums for both higher education groups up to the year 2000, indicating on ongoing shift toward higher paid cognitive jobs for college-educated workers.

Our primary goal is to understand and interpret the changes in the within and between components since the year 2000. For the college-only group, the within component continued to rise after the year 2000 at nearly the same rate as in the 1990 s, rising by about $3.5 \log$ points through 2010 and another 1.0 points through 2015 . However, this was offset by a decline in the between component of about $2 \log$ points from 2000 through 2015. This suggests that despite the increase in the college-only group's competitive advantage over lesser educated individuals within broad occupational groups, their overall wage advantage has been eroded slightly by a shift toward routine jobs. This is consistent with polarization or skill downgrading.

For the graduate degree group, the between effect did not decline after 2000, indicating that their occupational distribution has not shifted away from highly paid cognitive jobs. However, between 2010 and 2015, the wage gap between graduate degree holders and the college-only group within the same broad occupations fell by about $2 \log$ points, suggesting that the direct competitive edge afforded by graduate training may be eroding. This erosion of the within effect for the graduate group suggests that skill downgrading may be playing an increasingly important role at the top of the skill distribution.

These results are robust to alternative definitions for the four broad occupations groups, including re-organization of the routine and non-routine manual categories and separate treatment of selected services industries. ${ }^{17}$ I also investigated alternative decompositions based on industry rather than occupation categories. These analyses indicated that the level and

\footnotetext{
${ }^{17}$ I thank my discussant David Autor for emphasizing the importance of investigating alternative occupational groupings, based on his recent research (e.g., Autor and Dorn 2013).
} 
changes in higher education wage premiums are almost entirely determined within industries, with virtually no contribution coming from differences or changes over time in the wage premium and higher education shares across industries.

Overall, the results suggest rising competition between education groups for increasingly scarce well-paid jobs. Some of this is reflected in the movement of individuals holding only a college degree into routine jobs, consistent with polarization or skill downgrading, and some is reflected in the wage advantage of those with graduate degrees over the college-only group within broad occupations, suggesting skill downgrading.

\section{Discussion and conclusions}

I have documented a flattening in the U.S. higher education wage premium over the last few decades. In particular, after rising substantially in the 1980s, growth in the wage gap between individuals with a four-year college or graduate degree and those with a high school degree slowed progressively. The gaps have changed little since the year 2000, and they were flat to down during the period 2010-2015. These patterns suggest that the previously growing complementarity between highly educated labor and new production technologies, especially those that rely on computers and related organizational capital, may be leveling off.

I investigated these patterns with reference to two related explanations for changing U.S. employment patterns: (i) a shift away from middle-skilled occupations driven largely by technological change ("polarization;” e.g., Acemoglu and Autor 2011); and (ii) a general weakening in the demand for advanced cognitive skills that cascades down the skill distribution (“skill downgrading;" Beaudry, Green, and Sand 2016). Descriptive evidence and comparison of the higher education wage premiums within and between broad occupational groups suggests 
that both factors have played a role in the flattening of the overall premiums. Occupational employment shifts have held down the college-only premium somewhat since the year 2000, suggesting that college-educated workers are increasingly sliding down into routine jobs. This is consistent with polarization or skill downgrading. More recently, since 2010, the wage gap between graduate degree holders and the college-only group within the same broad occupations has declined somewhat, suggesting that graduate training may be providing less of a competitive edge than it has in the past. This suggests that skill downgrading may be playing an increasingly important role at the top of the skill distribution. Overall, the results suggest rising competition between education groups for increasingly scarce well-paid jobs.

These findings should not be interpreted as suggesting that college and graduate training are no longer sound financial investments, from an individual or social perspective. Recent analyses indicate that relative to financing costs, higher education yields positive net returns for most individuals who complete college (Abel and Deitz 2014, Autor 2014, Daly and Cao 2015). On the other hand, it is important to note that the wage premiums to higher education are likely to vary substantially across individuals. Although higher education may be financially advantageous on average, the flattening of returns as costs have continued to rise suggests that college may be an unfavorable financial investment for rising numbers of individuals. In these circumstance, individual variation in returns looms as an increasingly important issue for future research.

I have focused on demand-side factors propelling the relative wages of college graduates, but supply-side factors may be important as well (Acemoglu and Autor 2011, Autor 2014). Sorting out the relative contributions of a demand slowdown and supply speed-up may be a worthwhile endeavor for future research. Related to overall supply trends, the composition of the 
college-educated workforce may have shifted in important ways. For-profit college attendance has expanded rapidly since the year 2000, and subsequent wage increases appear limited, even for those who complete four-year undergraduate and graduate degrees at for-profit institutions (Cellini and Turner 2016). This may be holding down the returns to college estimated from the population of employed college graduates.

With these caveats in mind, I will conclude by nothing that my findings raise the possibility of an eroding relationship between technological advance and the returns to investment in higher education. If this interpretation proves to be correct and durable, it has potentially important implications for this volume's primary themes. Human capital has been a key engine of growth in developing and advanced economies alike. Slower growth in the returns to higher education suggest that this connection may be fraying, raising the possibility of continued slow growth ahead. 


\section{References}

Abel, Jaison R., and Richard Deitz. 2014. "Do the Benefits of College Still Outweigh the Costs?" Federal Reserve Bank of New York Current Issues in Economics and Finance 20(3). https://www.newyorkfed.org/medialibrary/media/research/current issues/ci20-3.pdf

Abel, Jaison R., and Richard Deitz. 2016. "Underemployment in the Early Careers of College Graduates Following the Great Recession.” Working paper, Federal Reserve Bank of New York. Forthcoming in this volume.

Acemoglu, Daron, and David Autor. 2011. "Skills, Tasks and Technologies: Implications for Employment and Earnings.” In Orley Ashenfelter and David Card, eds., Handbook of Labor Economics, Volume 4b: 1043-1171. Amsterdam: Elsevier-North Holland.

Autor, David H. 2014. "Skills, Education, and the Rise of Earnings Inequality Among the 'Other 99 Percent.'" Science 344 (6186, May 23): 843-851.

Autor, David H. 2015. "Polanyi's Paradox and the Shape of Employment Growth." Federal Reserve Bank of St. Louis: Economic Policy Proceedings, Reevaluating Labor Market Dynamics: 129-177. http://economics.mit.edu/files/9835

Autor, David H., and David Dorn. 2013. "The Growth of Low-Skill Service Jobs and the Polarization of the US Labor Market." American Economic Review 103(5): 1553-1597.

Autor, David H., David Dorn, and Gordon H. Hanson. 2013. "The China Syndrome: Local Labor Market Effects of Import Competition in the United States." American Economic Review 103(6): 2121-2168.

Autor, David H., Lawrence F. Katz, and Alan B. Krueger. 1998. “Computing Inequality: Have Computers Changed the Labor Market?" Quarterly Journal of Economics 113 (4, Nov.): 1169-1214.

Autor, David H., Frank Levy, and Richard J. Murnane. 2003. "The Skill Content of Recent Technological Change: An Empirical Exploration." Quarterly Journal of Economics 118 (4, Nov.): 1279-1333.

Beaudry, Paul, David A. Green, and Benjamin M. Sand. 2014. "The Declining Fortunes of the Young Since 2000.” American Economic Review 104(5, May): 381-86.

Beaudry, Paul, David A. Green, and Benjamin M. Sand. 2016. "The Great Reversal in the Demand for Skill and Cognitive Tasks.” Journal of Labor Economics 34 (S1, Part 2): S199-247.

Bound, John, and Johnson, George. 1992. "Changes in the Structure of Wages in the 1980s: An Evaluation of Alternative Explanations.” American Economic Review 83 (June): 371-92. 
Buchmueller, Thomas C., John DiNardo, and Robert G. Valletta. 2011. "The Effect of an Employer Health Insurance Mandate on Health Insurance Coverage and the Demand for Labor: Evidence from Hawaii." American Economic Journal: Economic Policy 3 (November), pp. 25-51.

Card, David. 1999. "The Causal Effect of Education on Earnings". In Orley Ashenfelter and David Card, editors, Handbook of Labor Economics, Volume 3. Amsterdam: Elsevier.

Cellini, Stephanie Riegg, and Nicholas Turner. 2016. "Gainfully Employed? Assessing the Employment and Earnings of For-Profit College Students Using Administrative Data." NBER Working Paper 22287, May.

Daly, Mary C., and Yifan Cao. 2015. “Does College Pay?” In Does College Matter? Federal Reserve Bank of San Francisco 2014 Annual Report. http://sffededucation.org/annualreport2014/\#college-essays/does-college-pay

DiNardo, John, Nicole M. Fortin, and Thomas Lemieux. 1996. "Labour Market Institutions and the Distribution of Wages, 1973-1992: A Semiparametric Approach." Econometrica 64(5, September): 1001-1044.

Goldin, Caudia, and Lawrence F. Katz. 2008. The Race Between Education and Technology. Cambridge: Harvard University Press.

Goos, Maarten, and Alan Manning. 2007. "Lousy and Lovely Jobs: The Rising Polarization of Work in Britain.” Review of Economics and Statistics, 89(1): 118-133.

Goos, Maarten, Alan Manning, and Anna Salomons. 2014. "Explaining Job Polarization: Routine-Biased Technological Change and Offshoring." American Economic Review, 104(8): 2509-2526.

Jaeger, David. 1997. "Reconciling the Old and New Census Bureau Education Questions: Recommendations for Researchers." Journal of Business and Economic Statistics 15(3, Jul.): 300-09.

Krueger, Alan. 1993. "How Computers Have Changed the Wage Structure: Evidence from Microdata, 1984-1989." Quarterly Journal of Economics 108 (1, Feb.): 33-60.

Lemieux, Thomas. 2006a. "Postsecondary Education and Increasing Wage Inequality." American Economic Review 96(2, May): 195-99.

Lemieux, Thomas. 2006b. "Increasing Residual Wage Inequality: Composition Effects, Noisy Data, or Rising Demand for Skill?” American Economic Review 96(3, June): 461-98.

Lemieux, Thomas. 2010. "What Do We Really Know About Changes in Wage Inequality?” In Katharine G. Abraham, James R. Spletzer, and Michael Harper, eds., Labor in the New Economy. Chicago: University of Chicago Press. 
Lindley, Joanne, and Stephen Machin. 2013. "The Rising Postgraduate Wage Premium." Working paper, London School of Economics, October.

http://personal.lse.ac.uk/machin/pdf/j1\%20sm\%20october\%202013.pdf. 
Table 1: Educational Attainment Shares and Real Hourly Wages

\begin{tabular}{|c|c|c|c|c|c|c|}
\hline & \multicolumn{6}{|c|}{ Panel A: Employment share } \\
\hline & (1) & (2) & (3) & (4) & (5) & (6) \\
\hline & 1980 & 1990 & 1992 & 2000 & 2010 & $\underline{2015}$ \\
\hline No degree ( $<12$ yrs. education) & 0.197 & 0.130 & 0.115 & 0.099 & 0.082 & 0.077 \\
\hline High school degree & 0.371 & 0.368 & 0.358 & 0.314 & 0.280 & 0.256 \\
\hline Some college & 0.205 & 0.238 & 0.259 & 0.280 & 0.280 & 0.278 \\
\hline College only (4-year) & 0.158 & 0.183 & 0.177 & 0.205 & 0.232 & 0.247 \\
\hline Graduate Degree & 0.069 & 0.081 & 0.090 & 0.103 & 0.126 & 0.143 \\
\hline \multicolumn{7}{|l|}{ Graduate degree by type } \\
\hline Master's & & & 0.068 & 0.075 & 0.094 & 0.107 \\
\hline Professional & & & 0.012 & 0.014 & 0.016 & 0.016 \\
\hline Doctoral & & & 0.010 & 0.013 & 0.016 & 0.019 \\
\hline
\end{tabular}

Panel B: Real Hourly Wage ( 2015 \$) (averages by group)

$\begin{array}{lcccccc} & (1) & (2) & (3) & (4) & (5) & (6) \\ & \underline{1980} & \underline{1990} & \underline{1992} & \underline{2000} & \underline{2010} & \underline{2015} \\ \text { No degree (<12 yrs. education) } & 14.19 & 12.84 & 12.47 & 13.03 & 13.22 & 13.56 \\ \text { High school degree } & 16.33 & 15.99 & 15.87 & 17.20 & 17.77 & 17.98 \\ \text { Some college } & 18.80 & 19.29 & 19.16 & 20.84 & 21.47 & 21.59 \\ \text { College only (4-year) } & 22.85 & 25.32 & 25.18 & 28.98 & 30.49 & 30.93 \\ \text { Graduate Degree } & 27.27 & 31.43 & 31.66 & 36.40 & 39.70 & 39.48 \\ \text { Graduate degree by type } & & & & & & \\ \quad \text { Master's } & & & 29.94 & 33.99 & 36.85 & 36.83 \\ \quad \begin{array}{l}\text { Professional } \\ \quad \text { Doctoral }\end{array} & & & 38.32 & 45.01 & 50.75 & 50.51 \\ \end{array}$

Note: Author's calculations from CPS monthly files (Panel A) and MORG files (Panel B); sample weights used. See Table 2 note for MORG sample description and counts. Master's degrees include MBAs along with a wide set of other master's degrees; professional degrees are J.D., M.D., and related. 


\section{Table 2: Composition-Adjusted Wage/Earnings Differentials (log points, relative to high school graduates)}

\begin{tabular}{|c|c|c|c|c|c|c|}
\hline \multirow{4}{*}{ Full sample } & \multicolumn{6}{|c|}{ Panel A: CPS MORG Data } \\
\hline & \multirow{3}{*}{$\begin{array}{c}(1) \\
\underline{1980} \\
\end{array}$} & \multirow{3}{*}{$\begin{array}{c}(2) \\
1990 \\
\end{array}$} & \multirow{3}{*}{$\begin{array}{c}(3) \\
1992 \\
\end{array}$} & \multirow{3}{*}{$\begin{array}{c}(4) \\
2000 \\
\end{array}$} & \multirow{3}{*}{$\begin{array}{c}(5) \\
2010 \\
\end{array}$} & \multirow{3}{*}{$\begin{array}{c}(6) \\
\underline{2015} \\
\end{array}$} \\
\hline & & & & & & \\
\hline & & & & & & \\
\hline \multirow[t]{2}{*}{ College degree or higher } & 0.304 & 0.449 & 0.464 & 0.518 & 0.566 & 0.566 \\
\hline & $(.003)$ & $(.003)$ & $(.003)$ & $(.004)$ & $(.004)$ & $(.005)$ \\
\hline \multirow[t]{2}{*}{ College only (4-year) } & 0.270 & 0.402 & 0.403 & 0.451 & 0.475 & 0.477 \\
\hline & $(.004)$ & $(.004)$ & $(.004)$ & $(.005)$ & $(.005)$ & $(.005)$ \\
\hline \multirow[t]{2}{*}{ Graduate degree } & 0.383 & 0.553 & 0.581 & 0.648 & 0.727 & 0.712 \\
\hline & $(.005)$ & $(.005)$ & $(.005)$ & $(.006)$ & $(.006)$ & $(.006)$ \\
\hline Observations & 121001 & 123111 & 119014 & 83314 & 85397 & 76789 \\
\hline \multicolumn{7}{|c|}{ College degree or higher sample } \\
\hline \multirow[t]{2}{*}{ Graduate degree } & 0.111 & 0.149 & 0.170 & 0.194 & 0.245 & 0.226 \\
\hline & $(.006)$ & $(.006)$ & $(.006)$ & $(.007)$ & $(.006)$ & $(.006)$ \\
\hline \multirow[t]{4}{*}{ Observations } & 27042 & 33334 & 32684 & 26789 & 32305 & 31572 \\
\hline & \multicolumn{6}{|c|}{ Panel B: CPS March Data } \\
\hline & (1) & (2) & (3) & (4) & $(5)$ & (6) \\
\hline & $\underline{1980}$ & $\underline{1990}$ & $\underline{1992}$ & $\underline{2000}$ & $\underline{2010}$ & $\underline{2014}$ \\
\hline \multicolumn{7}{|l|}{ Full sample } \\
\hline \multirow[t]{2}{*}{ College degree or higher } & 0.293 & 0.449 & 0.477 & 0.538 & 0.579 & 0.576 \\
\hline & $(.006)$ & $(.006)$ & $(.006)$ & $(.006)$ & $(.006)$ & $(.007)$ \\
\hline \multirow[t]{2}{*}{ College only (4-year) } & 0.260 & 0.400 & 0.415 & 0.468 & 0.488 & 0.488 \\
\hline & $(.007)$ & $(.007)$ & $(.007)$ & $(.006)$ & $(.007)$ & $(.007)$ \\
\hline \multirow[t]{2}{*}{ Graduate degree } & 0.368 & 0.557 & 0.593 & 0.680 & 0.740 & 0.725 \\
\hline & $(.009)$ & $(.009)$ & $(.009)$ & $(.008)$ & $(.008)$ & $(.008)$ \\
\hline Observations & 34258 & 38123 & 37143 & 52489 & 45575 & 43435 \\
\hline \multicolumn{7}{|c|}{ College degree or higher sample } \\
\hline \multirow[t]{2}{*}{ Graduate degree } & 0.102 & 0.155 & 0.174 & 0.206 & 0.244 & 0.230 \\
\hline & $(.011)$ & $(.010)$ & $(.010)$ & $(.009)$ & $(.008)$ & $(.009)$ \\
\hline Observations & 8184 & 10630 & 10709 & 16350 & 17608 & 17540 \\
\hline \multicolumn{7}{|c|}{$\begin{array}{l}\text { Samples are wage and salary workers age } 25-64 \text { for both data sources, restricted to full-time year-round workers } \\
\text { (annual hours }>=1750 \text { ) in the CPS March data. Dependent variable is } \ln \text { (hourly earnings) for the MORG data } \\
\text { and ln(weekly earnings) for the CPS March data, with allocated values dropped and top-code adjustments (see } \\
\text { the text and appendix). Composition adjustment relies on the inclusion of the following control variables (all } \\
\text { categorical): } 7 \text { age, } 3 \text { race/ethnic, married, female, married*female, } 8 \text { geographic divisions. }\end{array}$} \\
\hline
\end{tabular}




\section{Table 3: Within-Between Analysis of Higher Education Wage Premiums (CPS MORG Data, regressions by broad occupation groups)}

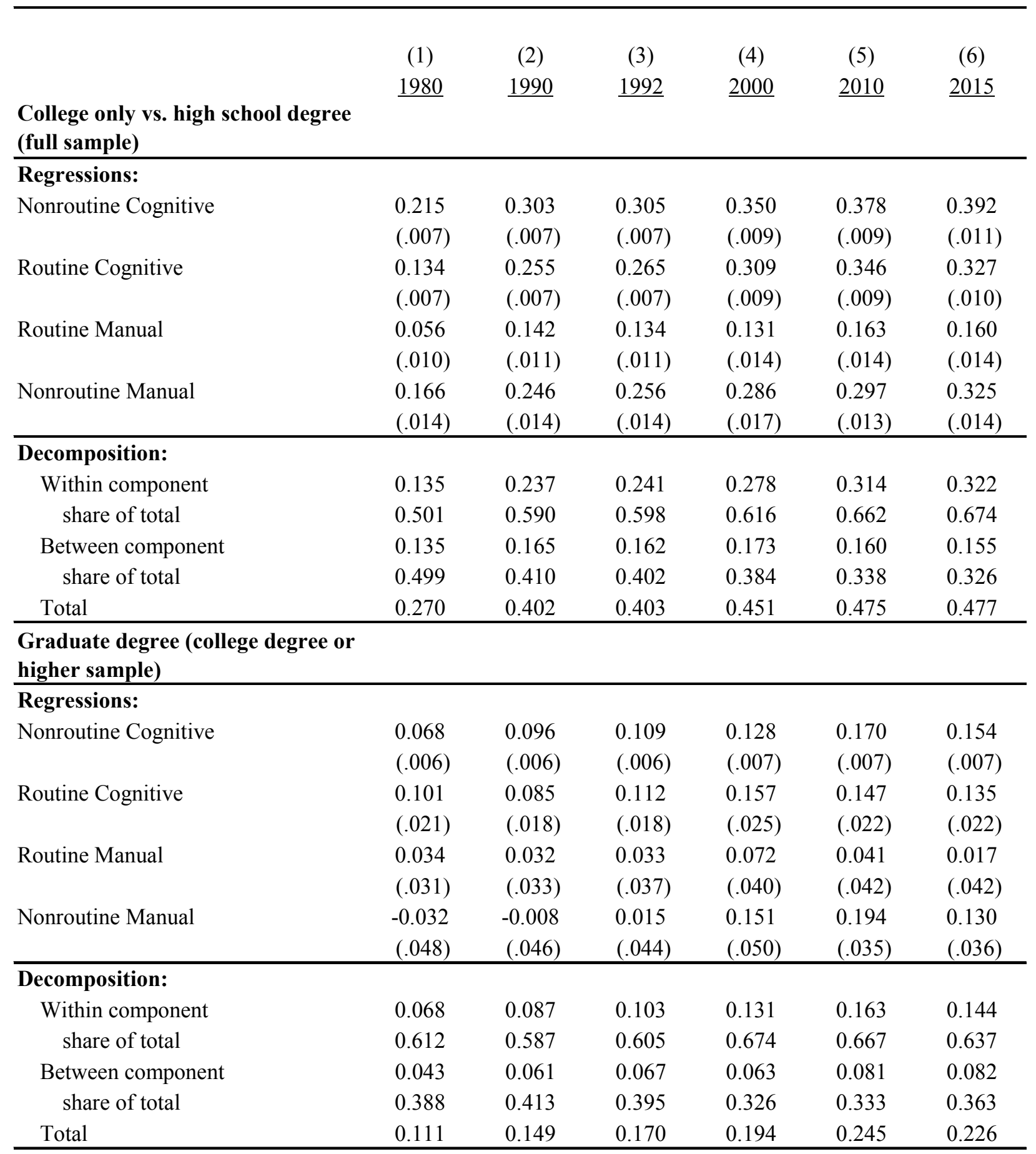

Note: See note to Table 2 for basic data and specification. Coefficients listed, with standard errors in parentheses; regressions run separately for each of the broad occupation groups listed, by year. See the text for a description of the decomposition. 
Figure 1: Estimated Higher Education Wage Premium, 1979-2015
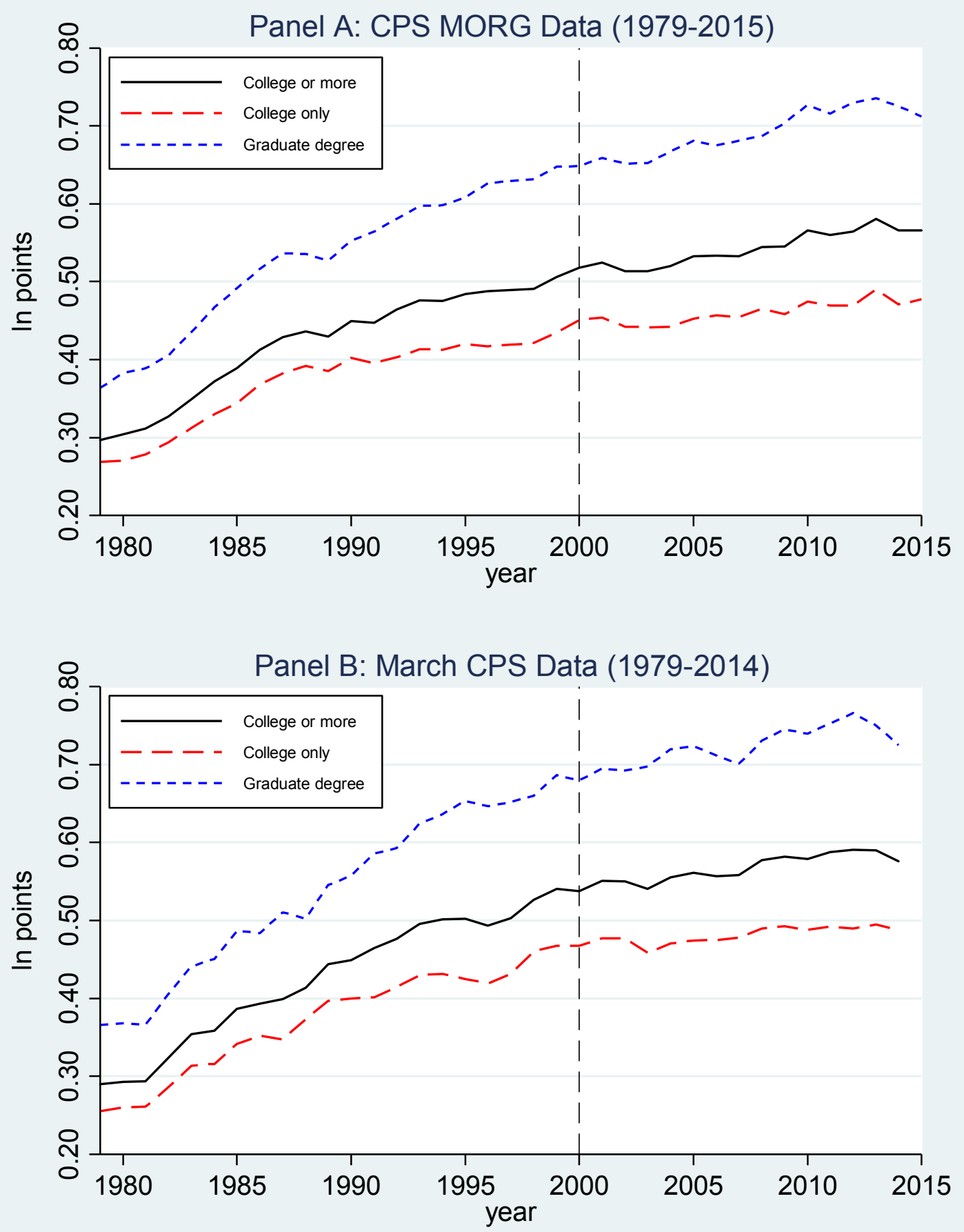

Note: Author's calculations using CPS MORG and March data (see Table 2 note). Differentials expressed relative to high school graduates. 
Figure 2: Estimated Graduate Degree Wage Premium

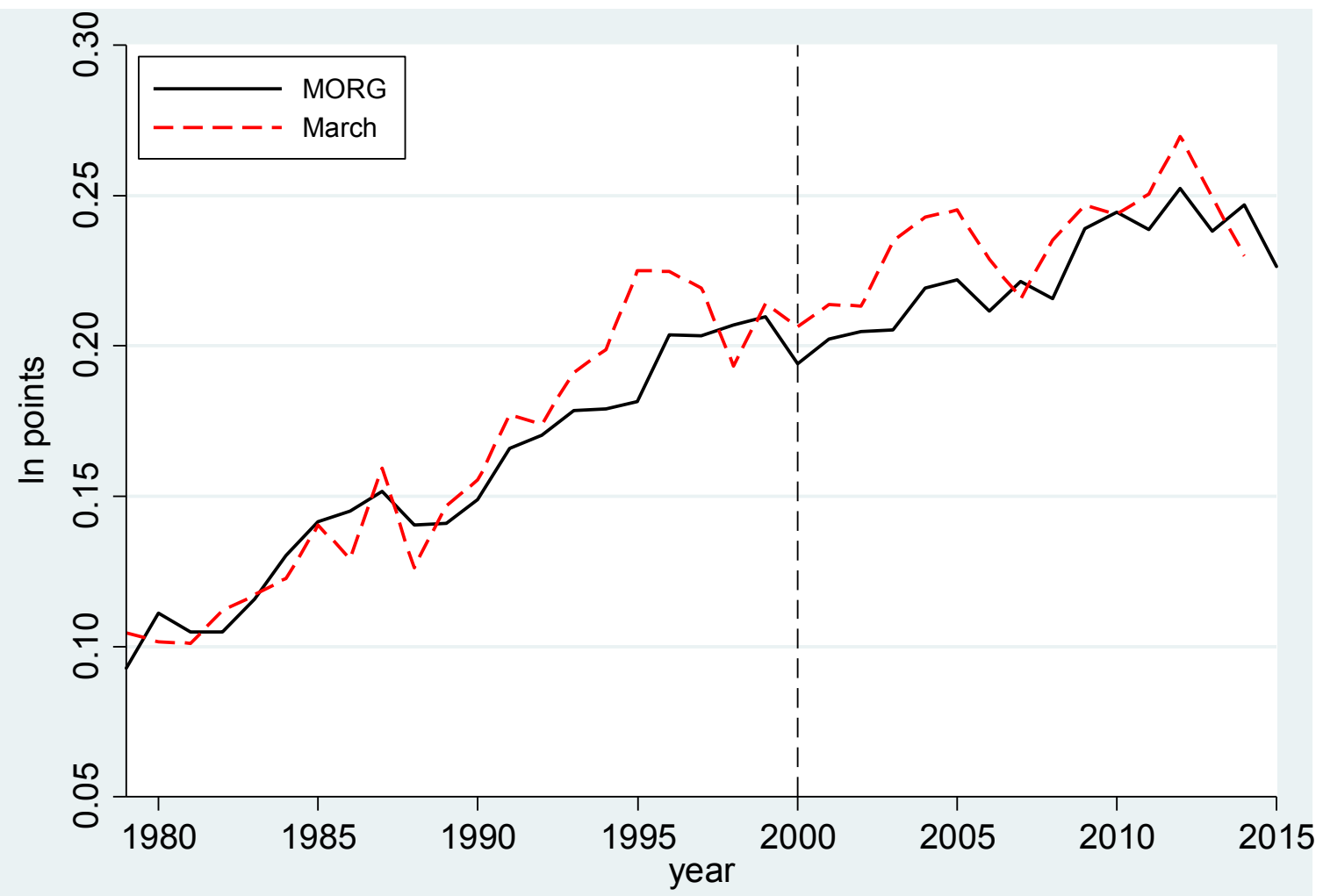

Note: Author's calculations using CPS MORG and March data (see Table 2 note). Differentials expressed relative to 4 -year college graduates. 
Figure 3: Estimated Higher Education Wage Premium, 1979-2015, by Age Group
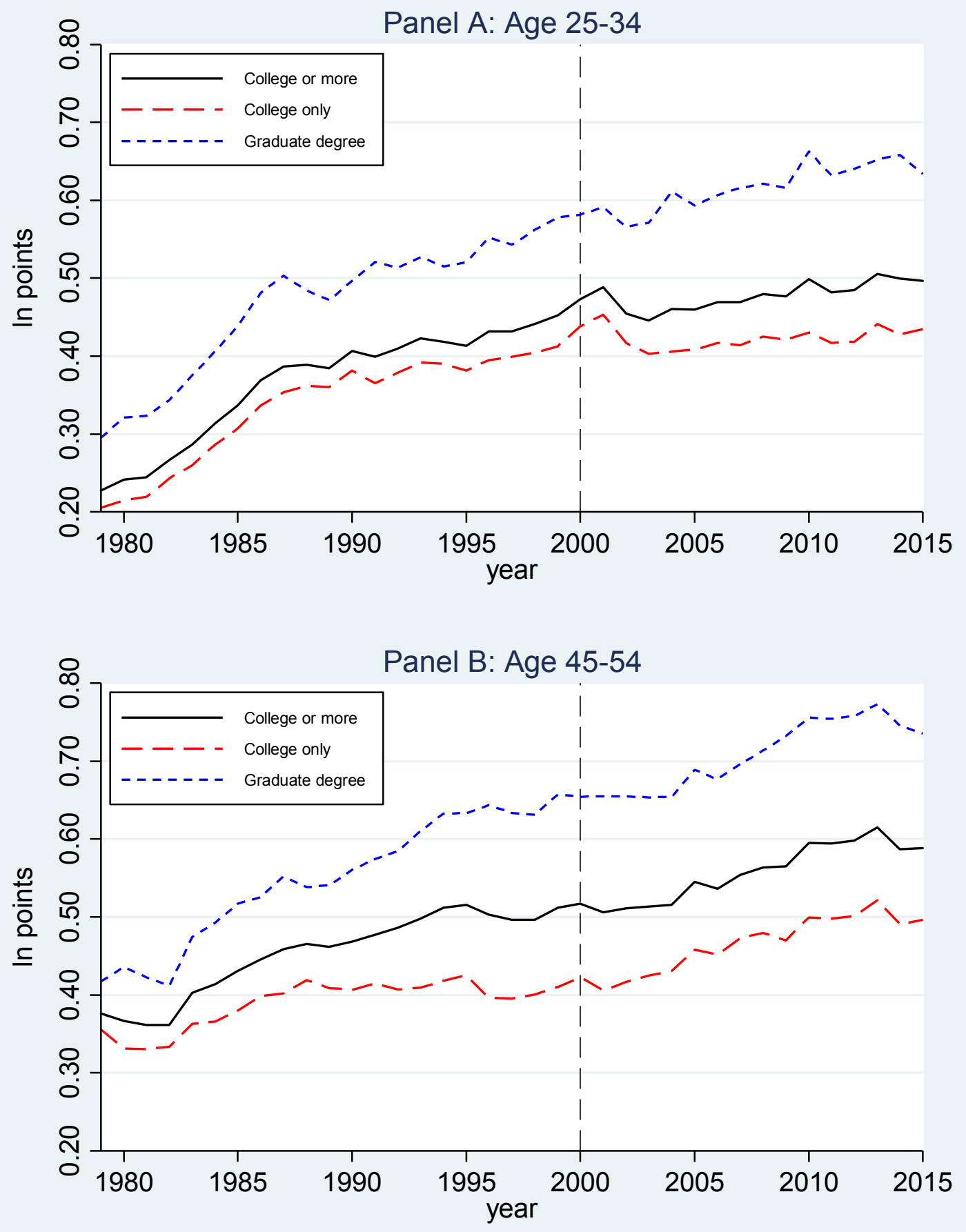

Note: Author's calculations using CPS MORG data (see Table 2 note). Differentials expressed relative to high school graduates. 


\section{Figure 4: Estimated Higher Education Wage Premium, 1979-2015,}

by Gender
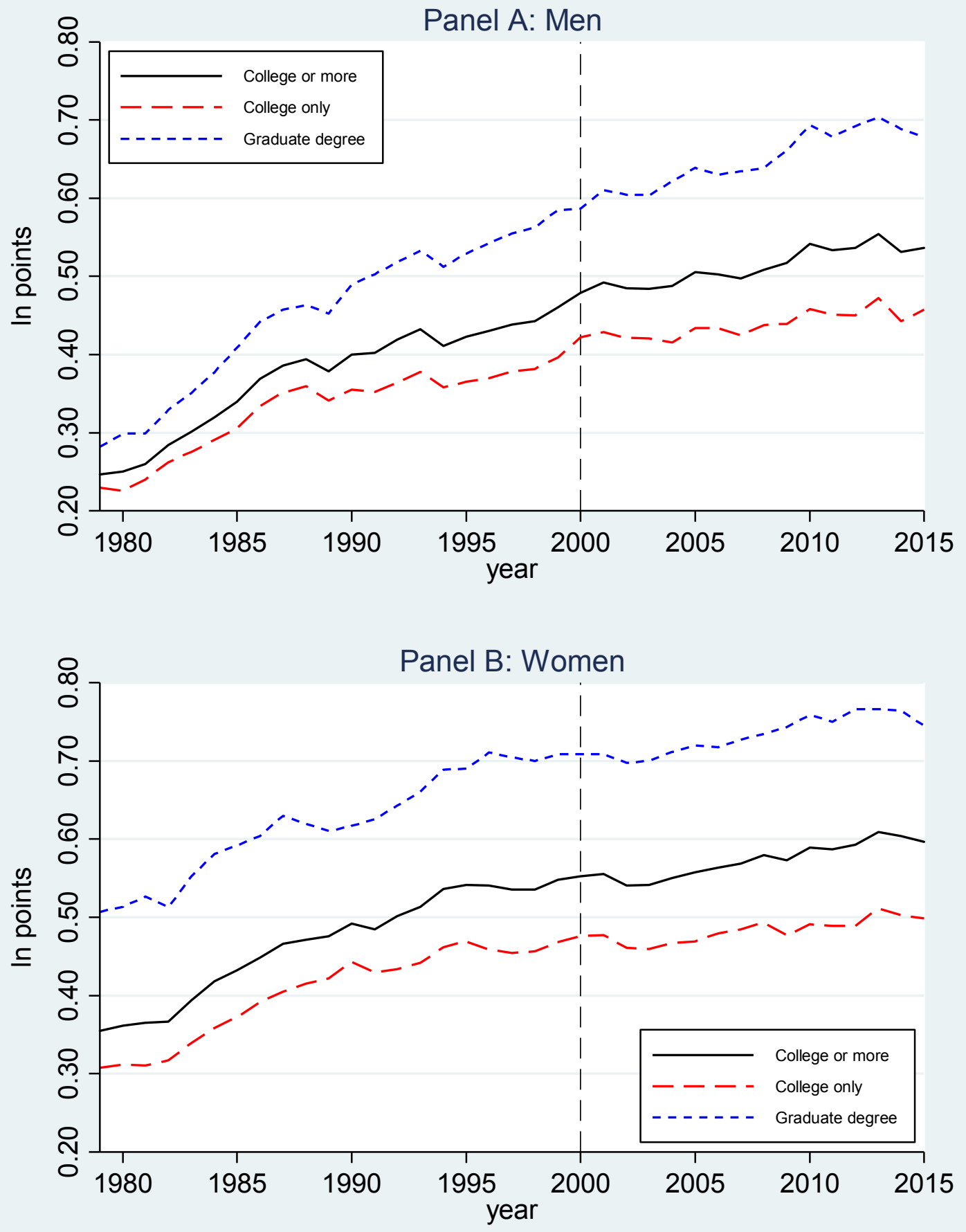

Note: Author's calculations using CPS MORG data (see Table 2 note). Differentials expressed relative to high school graduates. 
Figure 5: Employment Growth by Broad Occupation Category, Sub-Periods from 1983-2015

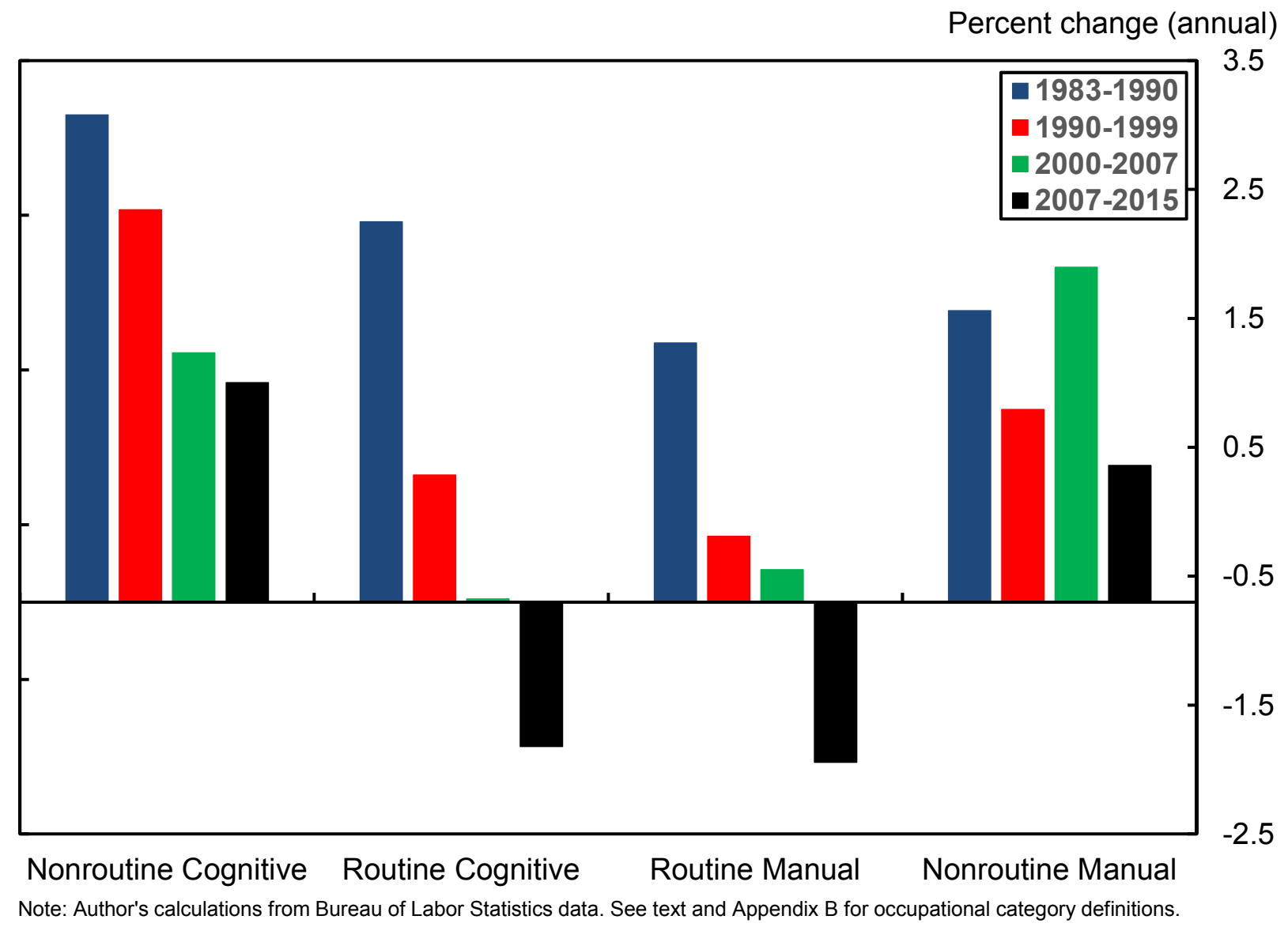


Figure 6: Higher Educational Attainment Shares by Occupational Category (selected), 1992-2015
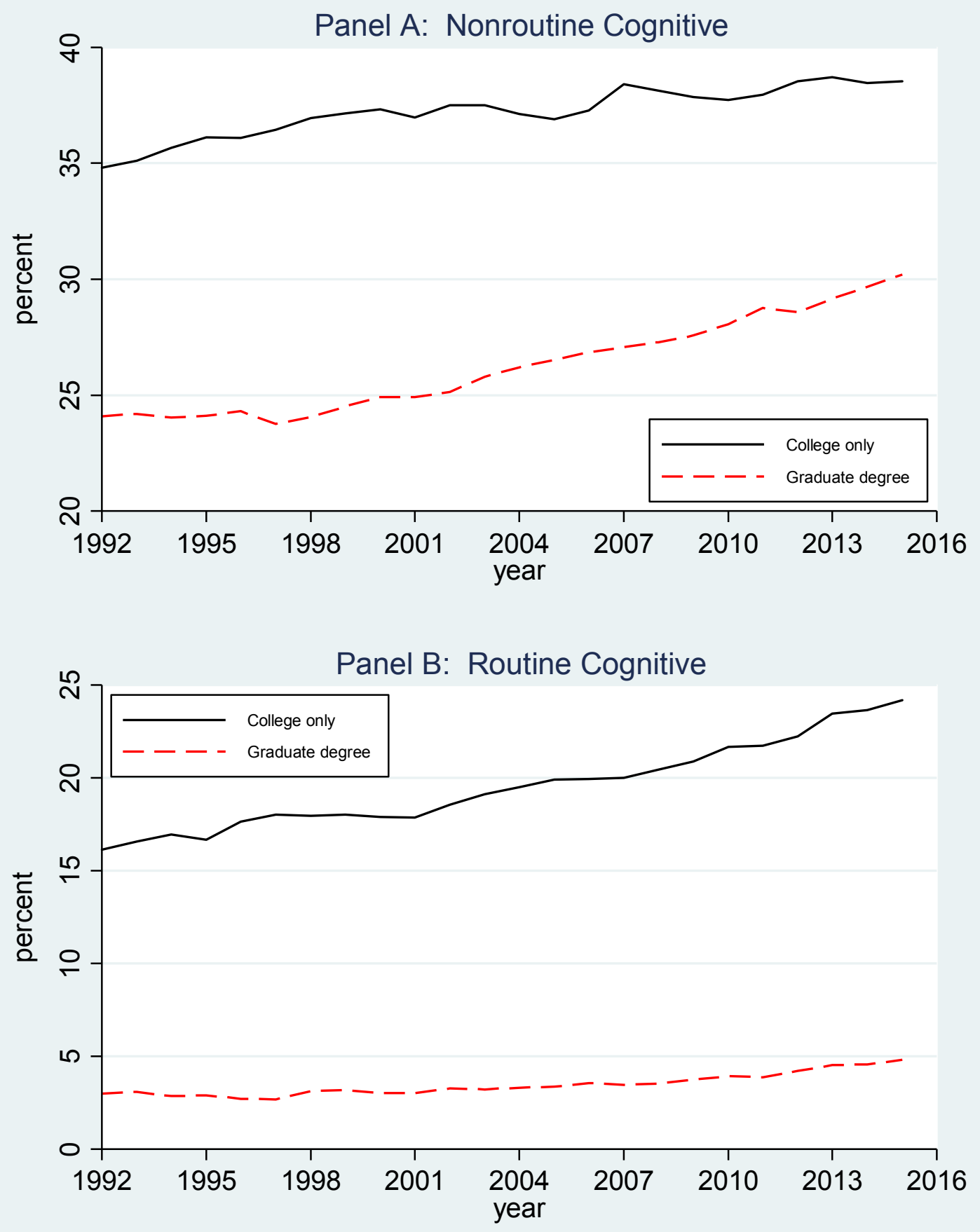

Note: Author's calculations using monthly CPS files. See text and Appendix B for occupational category definitions. Series are shares of educational attainment groups in the broad occupational categories. 
Figure 7: Share of Nonroutine Cognitive Employment by Educational Attainment, 1992-2015

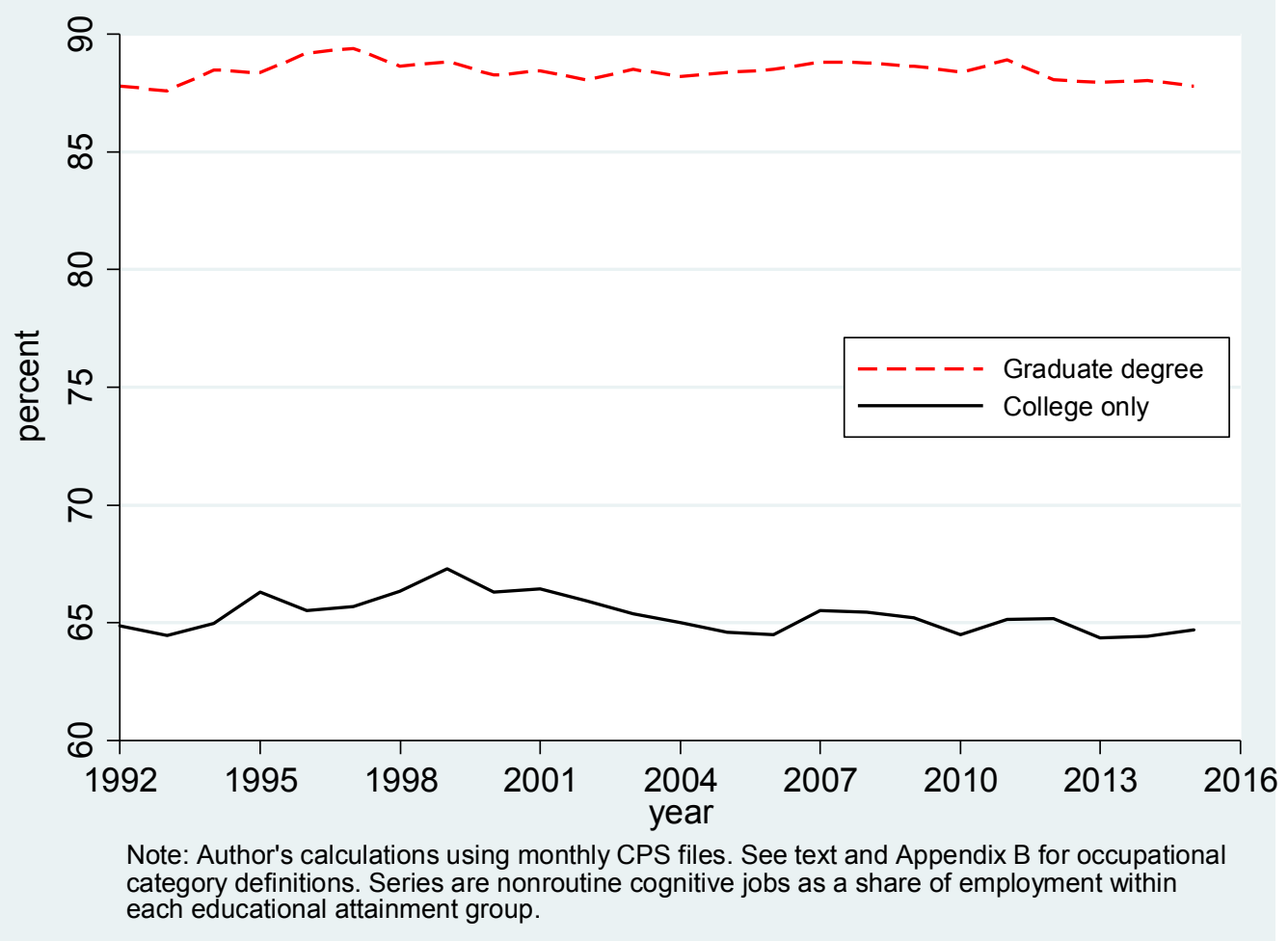


Figure 8: U.S. Productivity Growth, 1973-2016Q1 (with period averages)

\section{Labor Productivity}

Percent change from four quarters earlier; nonfarm business sector Percent

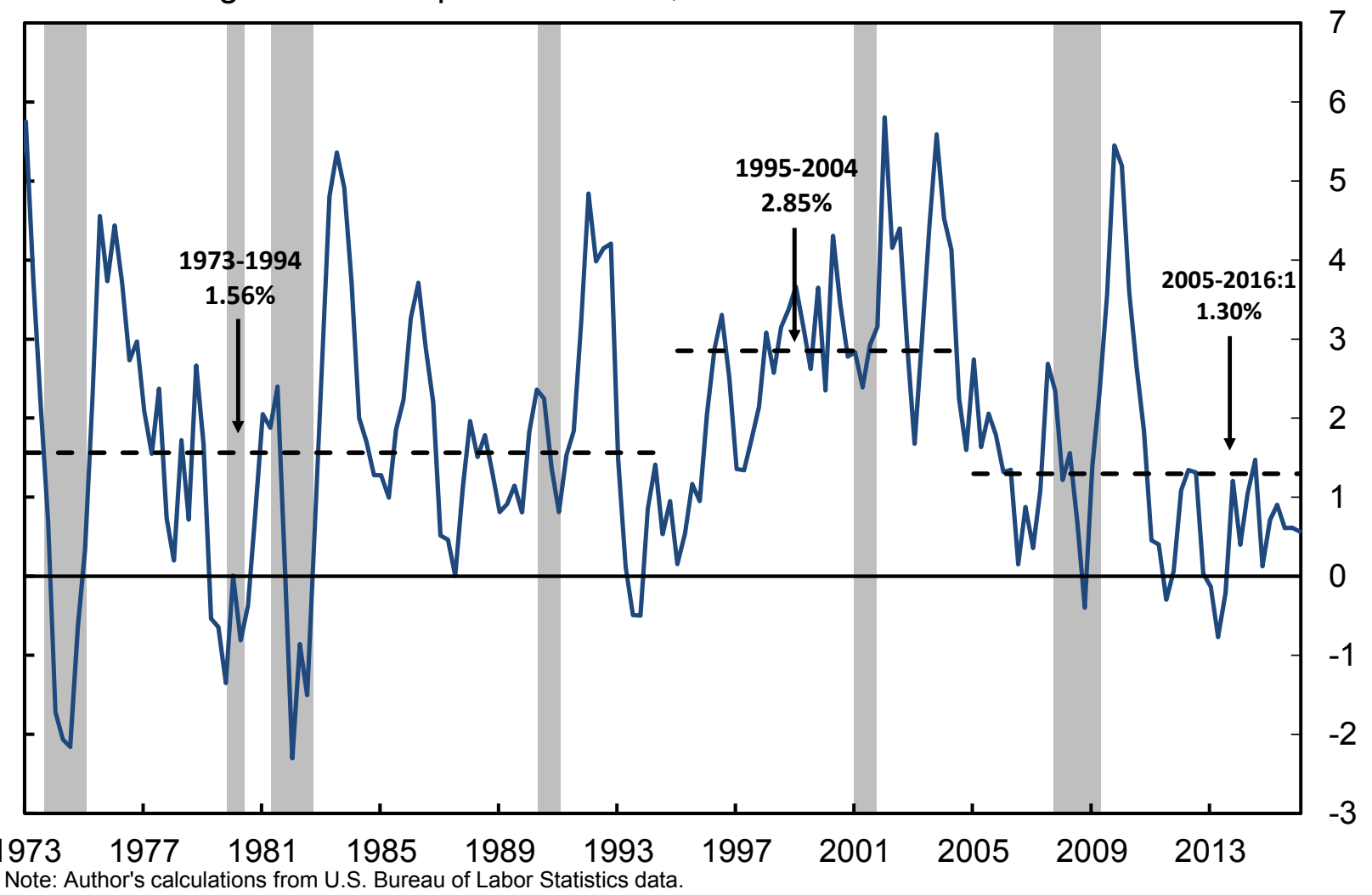


Figure 9: Total and Within/Between Wage Premiums, 1979-2015
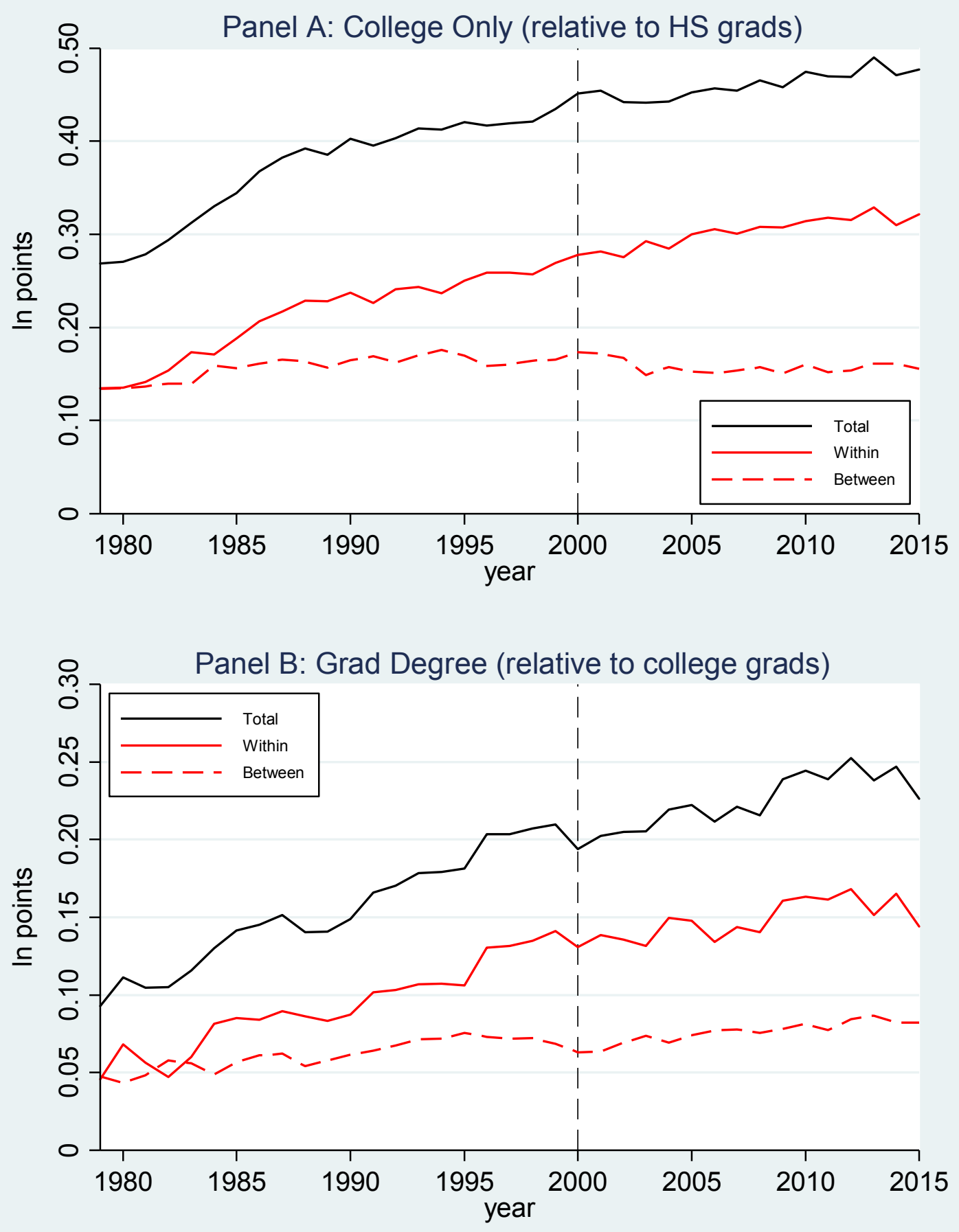

Note: See text and Table 3 for data and methods. Based on broad polarization occupation grouping (nonroutine cognitive, routine cognitive, routine manual, nonroutine manual). 


\section{Appendix A: MORG and March CPS Data}

The data handling and definitions for the CPS MORG and March data generally follow Lemieux (2006b, 2010) and Autor, Katz, and Kearney (2008); see also Buchmueller, DiNardo, and Valletta (2011). All analyses are limited to wage and salary workers age 25-64 (with farming and resource occupations excluded), and appropriate survey weights are used for all tabulated results.

MORG Data (definitions, top-coding, and imputation)

As noted in the text, I use hourly wages as my earnings measure, either reported directly by hourly workers or formed as usual weekly earnings divided by usual weekly hours worked for salaried workers. Wage levels are expressed in real terms using the GDP deflator for personal consumption expenditures.

Following Lemieux (2006b), the wage analyses are limited to individuals whose hourly wage is greater than $\$ 1$ and less than $\$ 100$ (in 1979 dollars); only a small number of observations are dropped due to this restriction. Recorded earnings are subject to maximum limits ("topcodes") in the public-use data files, which change over time. I multiplied the value of top-coded earnings observations by 1.4 . This largely follows Lemieux (2006), with the exception that for the sake of consistency over time, I did not rely on the higher top-code enabled by the use of unedited earnings values for the years 1989-1993.

As noted in past research, non-response to the earnings and hours questions in the CPS data and the consequent need to impute their values is substantial and has grown over time, potentially distorting analyses of wage differentials. Following common practice, I dropped observations with imputed values of earnings or hours worked from all wage analyses. I followed the procedures outlined in Lemieux (2006) for identifying imputed earnings 
observations. This includes the comparison of unedited and edited earnings values during the years 1989-1993, when the earnings imputation flags are incorrect. Imputation flags are missing for 1994 and most of 1995, which precludes dropping observations with imputed values during this period.

CPS March Annual Demographic Supplement Data (definitions, top-coding, and imputation)

I supplement the CPS MORG analyses using data from the CPS March Annual Demographic Supplement files. These files are currently available through 2015. Income data from the annual March supplement refer to the prior calendar year, so the reference period for the March data that I use ends one year earlier than the MORG data (2014 rather than 2015). As noted in the text, following standard practice, I restrict the March CPS sample to fulltime, full-year workers and use weekly earnings (annual labor earnings divided by weeks worked) as the earnings measure. The sample restriction with respect to real hourly wages (in 1979 dollars), the treatment of top-coded values, and the elimination of imputed earnings values are the same as described for the MORG data. 
Appendix B: Polarization Occupational Coding (excluding agriculture/resources)

\begin{tabular}{|c|c|}
\hline Broad polarization category & $\begin{array}{c}\text { Standard Occupational Classification (SOC) } \\
\text { major occupation groupings }\end{array}$ \\
\hline Non-Routine Cognitive & Management, business and financial operations \\
& (SOC 11, 13) \\
& Professional/technical (SOC 15-29) \\
\hline Routine Cognitive & Sales and related (SOC 41) \\
& Office and administrative support (SOC 34) \\
\hline Routine Manual & Construction and extraction (SOC 47) \\
& Installation/maintenance/repair (SOC 49) \\
& Production (SOC 51) \\
& Transportation and material moving (SOC 53) \\
\hline Non-Routine Manual & Healthcare support (SOC 31) \\
& Protective services (SOC 33) \\
& Food preparation and serving (SOC 35) \\
& Building and grounds (SOC 37) \\
& Personal care and service (SOC 39) \\
\hline
\end{tabular}

Note: 2010 SOC codes listed; earlier period codes harmonized. 